\title{
Assessment of the effect of the financial crisis on agents' expectations through symbolic regression
}

\author{
Oscar Claveria ${ }^{1}$, Enric Monte ${ }^{2}$, Salvador Torra ${ }^{3}$ \\ ${ }^{1}$ AQR-IREA, University of Barcelona (UB) \\ 2 Department of Signal Theory and Communications, Polytechnic University of Catalunya (UPC) \\ ${ }^{3}$ Riskcenter-IREA, Department of Econometrics and Statistics, University of Barcelona (UB)
}

Agents' perceptions on the state of the economy can be affected during economic crises. Tendency surveys are the main source of agents' expectations. The main objective of this study is to assess the impact of the 2008 financial crisis on agents' expectations. With this aim we evaluate the capacity of survey-based expectations to anticipate economic growth in the United States, Japan, Germany and the United Kingdom. We propose a symbolic regression (SR) via genetic programming (GP) approach to derive mathematical functional forms that link surveybased expectations to GDP growth. By combining the main SR-generated indicators, we generate estimates of the evolution of GDP. Finally, we analyse the effect of the crisis on the formation of expectations, and we find an improvement in the capacity of agents' expectations to anticipate economic growth after the crisis in all countries except Germany.

JEL Classification: C51, C55, C63, C83, C93, E27

Keywords: symbolic regression; evolutionary algorithms; genetic programming; tendency surveys; expectations; forecasting

\footnotetext{
* Corresponding Author:

Oscar Claveria, University of Barcelona, 08034 Barcelona, Spain. Email: oclaveria@ub.edu
} 


\section{Introduction}

Economic expectations are central in macro-economic time series modelling. Tendency surveys provide detailed information about agents' expectations, but the qualitative nature of agents' responses has led to quantify survey results. Numerous methods to transform responses about the expected direction of change into a quantitative measure of agents' expectations have been proposed in the literature. See Lahiri and Zhao (2015) and Nardo (2003) for an appraisal of the different quantification methods. The theoretical framework for quantifying survey expectations is based on the assumption that respondents report a variable to go up if the mean of their subjective probability distribution lies above a threshold level, also known as indifference interval (Theil, 1952). Carlson and Parkin (1975) developed this probability approach by using a normal distribution. Mitchell (2002) and Balcombe (1996) found evidence that normal distributions provided as accurate expectations as other stable distributions.

Several refinements of the probabilistic approach have been proposed in order to reduce the measurement error introduced by restrictive assumptions (Breitung and Schmeling, 2013; Mitchell et al., 2007; Löffler, 1999; Berk, 1999; Smith and McAleer, 1995; Pesaran, 1987; Batchelor, 1986). By comparing the individual responses with firmby-firm realizations, Müller (2010) developed a variant of the Carlson-Parkin method with asymmetric and time invariant thresholds. In a recent study, Lahiri and Zhao (2015) linked quantified expectations to quantitative realizations at the firm-level and obtained a significant improvement in accuracy by allowing for cross-sectional heterogeneity and asymmetric and time-varying thresholds, especially during periods of uncertainty with high levels of disagreement between respondents.

This result has led us to analyse the impact of the 2008 financial crisis on agents' expectations. The relationship between changes in expectations and economic variables has been widely investigated (Martinsen et al., 2014; Ghonghadze and Lux, 2012; Schmeling and Schrimpf, 2011; Franses et al., 2011; Graff, 2010; Klein and Özmucur, 2010; Claveria et al., 2007), but never before by means of symbolic regression (SR). SR can be regarded as an empirical modelling approach, particularly indicated to find the most fitting algebraic expression in large data sets, especially when the model structure is unknown or changes over time. 
By combining a SR approach with genetic programming (GP), we are able to quantify survey-based expectations and generate estimates of GDP growth. There are different strategies for finding a solution in SR. Koza (1992) proposed applying GP to implement SR in order to empirically assess the exchange equation. In spite of its versatility, GP applications in economics are still few (Álvarez-Díaz and Álvarez, 2005; AcostaGonzález et al., 2012).

With the aim of analysing the effect of the economic shock on the formation of agents' expectations in the United States (US), Japan, Germany and the United Kingdom (UK), we evaluate the capacity of the SR-generated estimations of GDP to anticipate economic growth, prior, during, and after the 2008 financial crisis. The empirical results show that the capacity of agents' expectations to anticipate economic growth improved after the crisis in all four economies.

\section{Experimental setup}

The experiment consists on designing a SR modelling strategy to find optimal combinations of survey expectations to estimate the year-on-year growth of the GDP. We link twelve survey indicators from the CESIfo World Economic Survey (WES) (Table 1) to year-on-year growth rates of quarterly GDP data from the OECD. The sample period goes from the second quarter of 2000 to the first quarter of 2014. See Hutson et al. (2014) and Claveria et al. (2016) for an appraisal of the CESIfo's WES.

Table 1

World Economic Survey (WES) - Survey indicators

\begin{tabular}{lll}
\hline & Expectations & \\
\hline Present & Compared to last year & For the next six months \\
\hline Economic situation & Economic situation & $\begin{array}{l}\text { Economic situation and } \\
\text { foreign trade volume }\end{array}$ \\
\hline $\begin{array}{l}\text { overall economy } \\
\text { capital expenditures } \\
\text { private consumption }\end{array}$ & overall economy & $\begin{array}{l}\text { overall economy } \\
\text { capital expenditures }\end{array}$ \\
& capital expenditures \\
& & $\begin{array}{l}\text { private consumption } \\
\text { volume of exports }\end{array}$ \\
& & volume of imports \\
& & trade balance \\
\hline
\end{tabular}

By means of SR we derive building blocks defined as simple combinations of survey variables. From the expressions returned by the GP algorithm for 28 countries of the OECD, we combine the most fitted empirical functions to generate a SR-indicator 
that is used to forecast economic growth in the US, Japan, Germany and the UK. In Table 2 we present a detailed description of the parameters of the experiment.

Regarding the termination criterion, we set a maximum number of 150 generations. We use the Distributed Evolutionary Algorithms Package (DEAP) framework implemented in Python.

\section{Table 2}

\begin{tabular}{ll} 
Description of the experiment \\
\hline Parameter & Value \\
\hline Population size & 1000 \\
Max. generations & 150 \\
Parent selection & Tournament size $=3$ \\
Replacement & 1-Elitism \\
Initialization & Select 1000 best of random sample of size 2000 \\
Crossover & Sub-tree-swapping \\
Mutation & With prob. 0,1, create a branch with a new individual \\
Tree constraints & Dynamic depth limit (initial limit $=7)$ \\
Model selection & Best on validation \\
Stopping criterion & max. Generations \\
Fitness function & RMSE \\
Function set & $\{+,-, *, /$, avg_4, log(.)sign(.), (.)^2, sqrt(.)sign(.), max_4(.), min_4(.) $\}$ \\
Terminal & Set constants=\{0,5-1,10,5 $\},$ variables \\
\hline
\end{tabular}

\section{Results}

The empirical analysis is divided in two parts. First, we graphically compare the evolution of the proposed SR-generated indicator, which can be regarded as a proxy for economic growth, to that of the Economic Climate Index (ECI) and the GDP (Fig. 1). The ECI is an aggregate indicator obtained as the arithmetic mean of the assessments about the general economic situation and the expectations for the economic situation in the next six months (CESifo World Economic Survey, 2011).

Fig. 1 shows that the proposed SR-generated indicator and the ECI show a similar pattern of evolution, closely correlated to the oscillations of GDP. Girardi (2014), JeanBaptiste (2012), and Qiao et al. (2009) find evidence that survey expectations provide useful information for forecasting purposes. The main difference between both indicators resides in the scale. This is especially evident during the 2008 financial crisis, when the quantified expectations' downward reaction is of greater magnitude than that of the ECI. 
Fig. 1

Evolution of year-on-year GDP growth rates vs. survey-based economic indicators

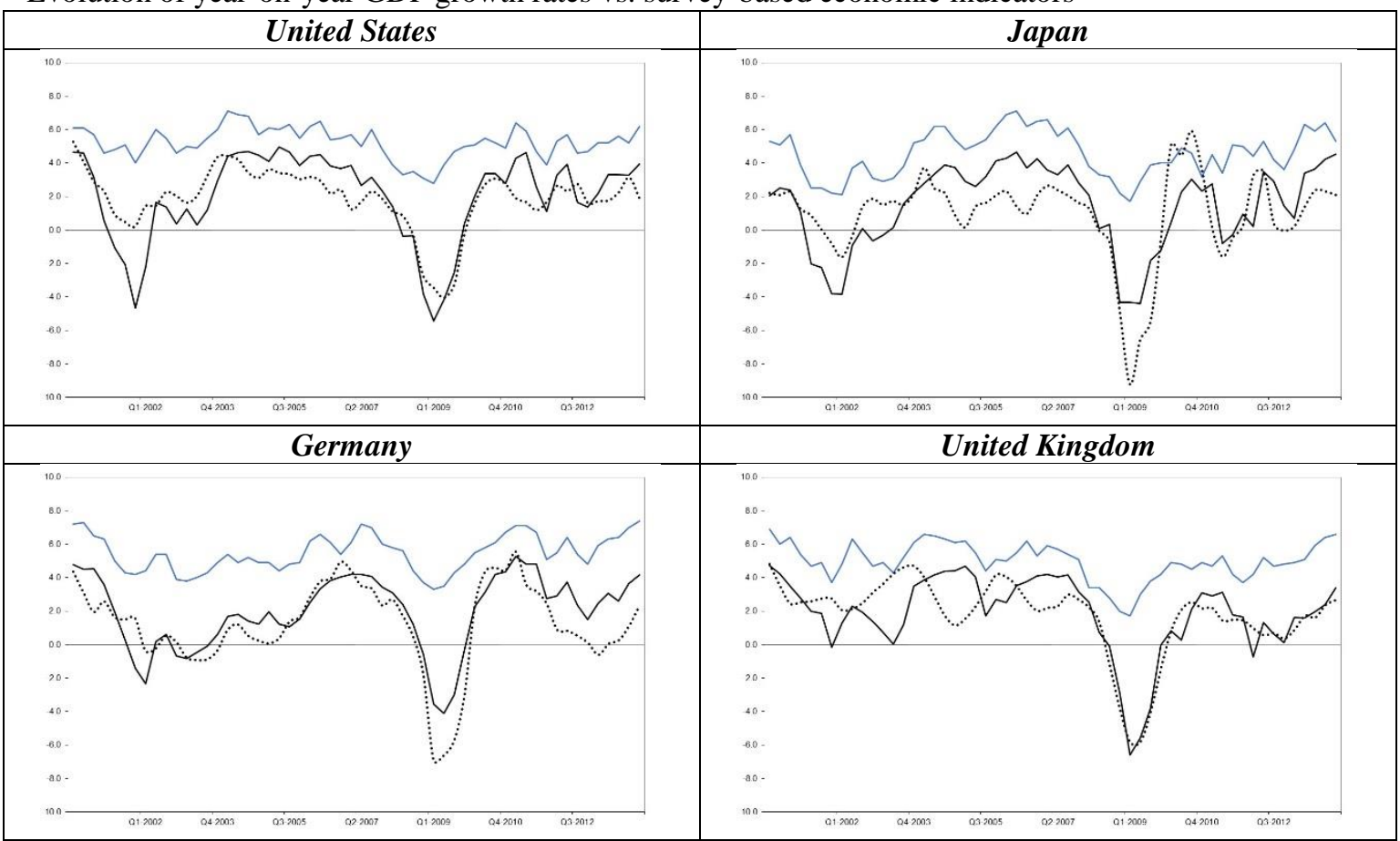

1. Note: The black line represents the year-on-year growth rate of GDP in each country. The grey line represents the evolution of the Ifo Economic Climate indicator. The black dotted line represents the evolution of the proposed indicator.

To analyse whether the 2008 financial crisis has had an influence on the forecast accuracy of survey-based measures of economic expectations, we evaluate the forecasting performance of the SR-generated estimates of GDP, differentiating between the pre-crisis sub-period (2000-2007), the crisis (2008-2010), and the post-crisis subperiod. We compute the mean absolute scaled error (MASE) proposed by Hyndman and Koehler (2006), which scales the errors by the MAE obtained with a random walk. As official data are published with a delay of more than a quarter with respect to survey data, we use two-step ahead naïve forecasts as a benchmark. Results of this comparison are presented in Table 3.

The results in Table 3 show that the forecast accuracy of survey-based expectations significantly improved during the crisis. Agents' expectations have been more accurate in the post-crisis years than in the pre-crisis years in all countries except Germany. Japan is the only country where agents' expectations are always more accurate than the predictions obtained with the benchmark model. These results are in line with those of Łyziak and Mackiewicz-Łyziak (2014), who found that the 2008 financial crisis period had led to a decrease in expectational errors in transition economies. 
Table 3

Forecast accuracy by country

\begin{tabular}{llll}
\hline & MASE & & MASE \\
\hline United States & 1.054 & Germany & $\mathbf{0 . 7 3 7}$ \\
Japan & $\mathbf{0 . 8 2 5}$ & United Kingdom & $\mathbf{0 . 8 8 0}$ \\
\hline MASE & Pre-crisis & Crisis & Post-crisis \\
\hline United States & 1.241 & $\mathbf{0 . 6 9 3}$ & 1.109 \\
Japan & $\mathbf{0 . 7 9 9}$ & $\mathbf{0 . 9 2 6}$ & $\mathbf{0 . 7 5 3}$ \\
Germany & $\mathbf{0 . 5 4 2}$ & $\mathbf{0 . 7 2 5}$ & 1.156 \\
United Kingdom & 1.197 & $\mathbf{0 . 6 8 8}$ & $\mathbf{0 . 4 5 7}$
\end{tabular}

Note: MASE stands for the Mean Absolute Scaled Error. Below one values (in bold) indicate better predictions than the average two-step forecast computed in-sample with the naïve method.

\section{Conclusion}

This paper proposes a data-driven approach to derive quantitative estimates of GDP from qualitative survey responses about the state of the economy by means of SR via GP. With the aim of analysing the impact of the 2008 financial crisis on agents' expectations, we assess the capacity of SR-generated expectations to anticipate future economic growth, prior, during, and after the financial crisis, finding that the crisis period has led to an improvement in the forecasting performance of agents' expectations in all countries except Germany.

\section{References}

Acosta-González, E., Fernández, F., Sosvilla, S. 2012. On factors explaining the 2008 financial crisis. Economics Letters 115, 215-217.

Álvarez-Díaz, M., Álvarez, A. 2005. Genetic multi-model composite forecast for non-linear prediction of exchange rates. Empirical Economics 30, 643-663.

Balcombe, K. 1996. The Carlson-Parkin method applied to NZ price expectations using QSBO survey data. Economics Letters 51, 51-57.

Batchelor, R.A. 1986. Quantitative v. qualitative measures of inflation expectations. Oxford Bulletin of Economics and Statistics 48, 99-120.

Berk, J. M. 1999. Measuring inflation expectations: a survey data approach. Applied Economics 31, 1467-1480.

Breitung, J., Schmeling, M. 2013. Quantifying survey expectations: What's wrong with the probability approach? International Journal of Forecasting 29, 142-154.

Carlson, J.A., and Parkin, M. 1975. Inflation expectations. Economica 42, 123-138.

CESifo World Economic Survey. 2011. Volume 10, No. 2, May 2011. 
Claveria, O., Monte, E., Torra, S. 2016. A self-organizing map analysis of survey-based agents' expectations before impending shocks for model selection: The case of the 2008 financial crisis. International Economics. In press.

Claveria, O., Pons, E., Ramos, R. 2007. Business and consumer expectations and macroeconomic forecasts. International Journal of Forecasting 23, 47-69.

Franses, P.H., Kranendonk, H.C., Lanser, D. 2011. One model and various experts: Evaluating Dutch macroeconomic forecasts. International Journal of Forecasting 27, 482-495.

Ghonghadze, J., Lux, T. 2012. Modelling the dynamics of EU economic sentiment indicators: An interaction-based approach. Applied Economics 44, 3065-3088.

Girardi, A. 2014. Expectations and macroeconomic fluctuations in the euro area. Economics Letters 125, 315-318.

Graff, M. 2010. Does a multi-sectoral design improve indicator-based forecasts of the GDP growth rate? Evidence from Switzerland. Applied Economics 42, 2759-2781.

Hutson, M., Joutz, F., Stekler, H. 2014. Interpreting and evaluating CESIfo's World Economic Survey directional forecasts. Economic Modelling 38, 6-11.

Hyndman, R.J., Koehler, A.B. 2006. Another look at measures of forecast accuracy. International Journal of Forecasting 22, 679-688.

Jean-Baptiste, F. 2012. Forecasting with the new Keynesian Phillips curve: Evidence from survey data. Economics Letters 117, 811-813.

Klein L.R., Özmucur S. 2010. The use of consumer and business surveys in forecasting. Economic Modelling 27, 1453-1462.

Koza, J.R. 1992. Genetic programming: On the programming of computers by means of natural selection. Cambridge, MA: MIT Press.

Lahiri, K., Zhao, Y. 2015. Quantifying survey expectations: A critical review and generalization of the Carlson-Parkin method. International Journal of Forecasting 31, 51-62.

Löffler, G. 1999. Refining the Carlson-Parkin method. Economics Letters 64, 167-71.

Łyziak, T., Mackiewicz-Łyziak, J. 2014. Do consumers in Europe anticipate future inflation? Eastern European Economics 52, 5-32.

Martinsen, K., Ravazzolo, F., Wulfsberg, F. 2014. Forecasting macroeconomic variables using disaggregate survey data. International Journal of Forecasting 30, 65-77.

Mitchell, J. 2002. The use of non-normal distributions in quantifying qualitative survey data on expectations. Economics Letters 76, 101-107.

Mitchell, J., Mouratidis, K., Weale, M. 2007. Uncertainty of UK manufacturing: Evidence from qualitative survey data. Economic Letters 94, 245-252.

Müller, C. 2010. You CAN Carlson-Parkin. Economics Letters 108, 33-35.

Nardo, M. 2003. The quantification of qualitative data: a critical assessment. Journal of Economic Surveys 17, 645-668.

Pesaran, M. H. 1987. The limits to rational expectations. Oxford: Basil Blackwell.

Qiao, Z., McAleer, M., Wong, W.K. 2009. Linear and nonlinear causality between changes in consumption and consumer attitudes. Economic Letters 102, 161-164.

Schmeling, M., Schrimpf, A. 2011. Expected inflation, expected stock returns, and money illusion: What can we learn from survey expectations. European Economic Review 55, 702-719.

Smith, J., McAleer, M. 1995. Alternative procedures for converting qualitative response data to quantitative expectations: an application to Australian manufacturing. Journal of Applied Econometrics 10, 165-185.

Theil, H. 1952. On the time shape of economic microvariables and the Munich Business Test. Revue de 1'Institut International de Statistique 20, 105-20. 